\title{
Surface Preparation Techniques for Adhesive Bonding of Aluminum and Copper
}

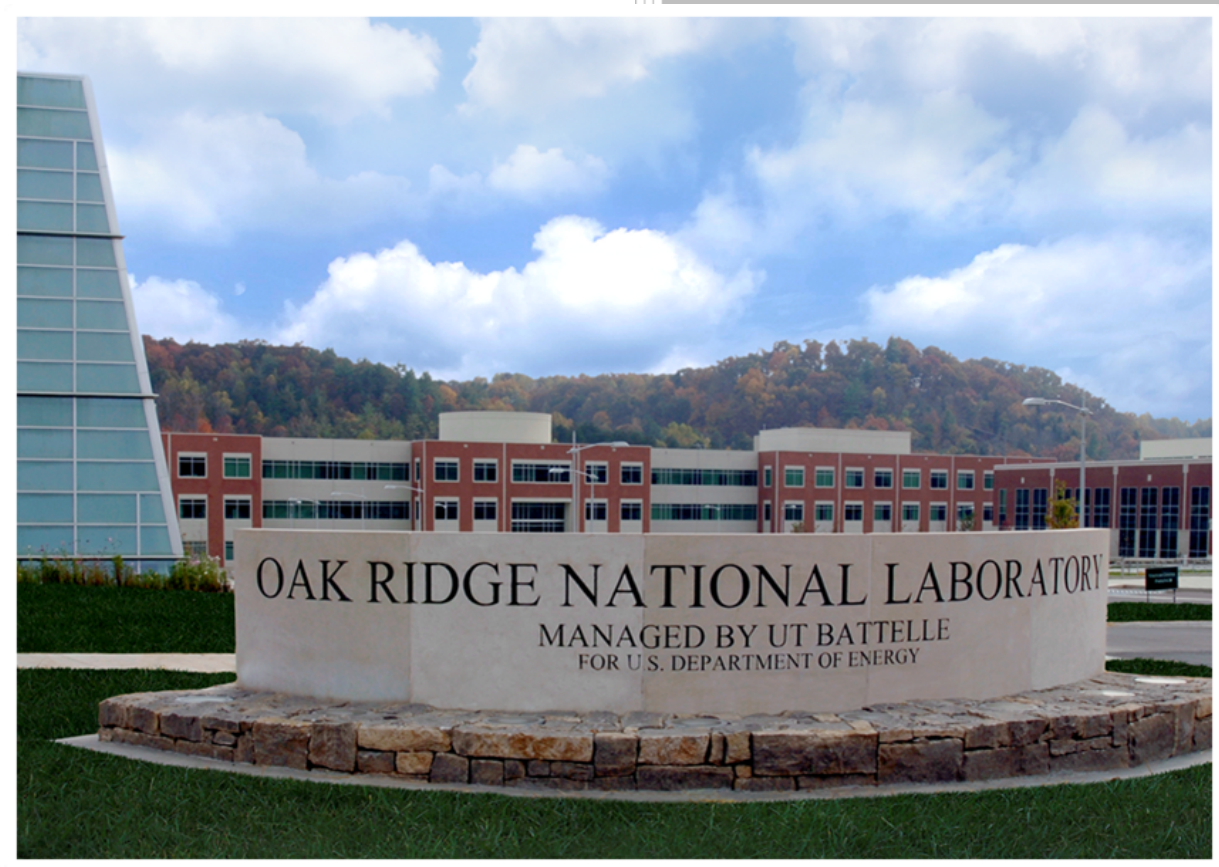

Approved for public release.

Distribution is unlimited.

Adrian S. Sabau

Haotian Liu

Justin A. Weibel

Eckhard A. Groll

Patrick Geoghegan

$3 / 31 / 2017$ 


\section{DOCUMENT AVAILABILITY}

Reports produced after January 1, 1996, are generally available free via US Department of Energy (DOE) SciTech Connect.

Website http://www.osti.gov/scitech/

Reports produced before January 1, 1996, may be purchased by members of the public from the following source:

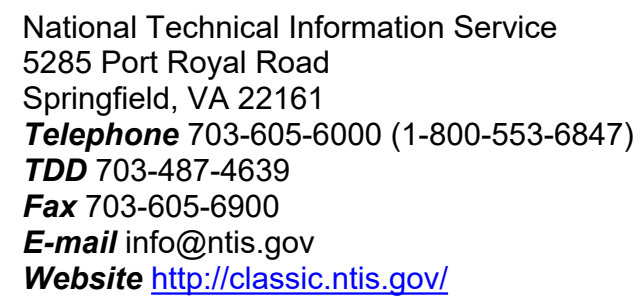

Reports are available to DOE employees, DOE contractors, Energy Technology Data Exchange representatives, and International Nuclear Information System representatives from the following source:

Office of Scientific and Technical Information

PO Box 62

Oak Ridge, TN 37831

Telephone 865-576-8401

Fax 865-576-5728

E-mail reports@osti.gov

Website http://www.osti.gov/contact.html

This report was prepared as an account of work sponsored by an agency of the United States Government. Neither the United States Government nor any agency thereof, nor any of their employees, makes any warranty, express or implied, or assumes any legal liability or responsibility for the accuracy, completeness, or usefulness of any information, apparatus, product, or process disclosed, or represents that its use would not infringe privately owned rights. Reference herein to any specific commercial product, process, or service by trade name, trademark, manufacturer, or otherwise, does not necessarily constitute or imply its endorsement, recommendation, or favoring by the United States Government or any agency thereof. The views and opinions of authors expressed herein do not necessarily state or reflect those of the United States Government or any agency thereof. 
Adhesive Bonding of Aluminum \& Copper in HVAC\&R Applications

\title{
SURFACE PREPARATION TECHNIQUES FOR ADHESIVE BONDING OF ALUMINUM AND COPPER
}

\author{
Adrian Sabau \\ Haotian Liu* \\ Justin A. Weibel* \\ Eckhard A. Groll* \\ Patrick Geoghegan
}

Date Published:

\author{
Prepared by \\ OAK RIDGE NATIONAL LABORATORY \\ Oak Ridge, TN 37831-6283 \\ managed by \\ UT-BATTELLE, LLC \\ for the \\ US DEPARTMENT OF ENERGY \\ under contract DE-AC05-00OR22725
}

*Purdue University, Ray W. Herrick Laboratories, groll@purdue.edu 
*Purdue University, Ray W. Herrick Laboratories, groll@purdue.edu 


\section{CONTENTS}



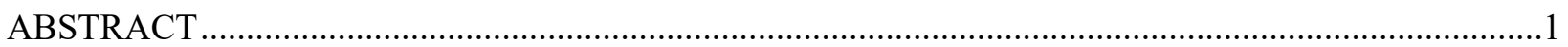



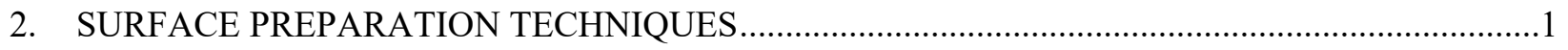

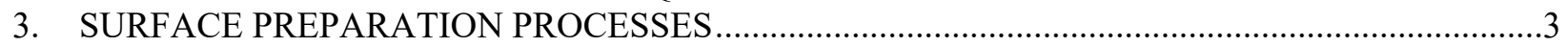



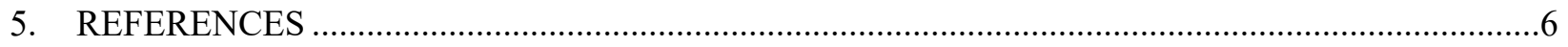




\begin{abstract}
Adhesive bonding is a commonly used technique to join different parts or structures. The bonding is attributed surface adhesion. Adhesion is defined by the ASTM Error! Reference source not found. as "the state in which two surfaces are held together by interfacial forces which consist of valence force or interlocking action or both." Both of these are highly dependent on the surface conditions, which makes the surface preparation very critical to the performance of adhesive bonding.

Obtaining a strong adhesive bond requires various considerations. Wegman and Levi Error! Reference source not found. describe several key steps of adhesive bonding that are summarized here: receiving materials, knowledge of the fabrication process for the parts, mating the parts to be bonded, and surface preparation. Among all these steps, surface preparation is usually the most critical, complex, and frequently neglected step in the bonding sequence. Surface preparation can remove the intermediate surface, paint, rust or oxide layer. Different materials including adherents, adhesives, and chemicals require different surface preparation techniques but in general, the surface preparation needs to consider the cleanliness, roughness, and functionality of the surface.
\end{abstract}

Adhesive bonding techniques specific to Aluminum and Copper are highlighted.

\title{
1. INTRODUCTION
}

Adhesive joining is an enabling technology that reduces the time, cost, and labor-intensive nature of Heating, Ventilation, Air-conditioning and Refrigeration (HVAC\&R) joining by at least a factor of 10 compared with current practices.

Aluminum heat exchanger joining uses high temperature furnaces (controlled atmosphere brazing) that are large power consumers. The joints have reliability issues and the joining to the Copper tubing can suffer from galvanic corrosion.

Copper based heat exchangers are brazed using a naked flame and highly flammable pressurized gas. Fire safety equipment must be on hand and inert gas purging is necessary during brazing to prevent contamination.

Adhesive joining will remove galvanic potential, reduce the size of heat exchangers, reduce the refrigerant volume, reduce the need for high temperature furnaces, and lead to lower stress levels and therefore greater reliability. This report details the techniques that may be employed to prepare the Copper and Aluminum surfaces for adhesive bonding.

\section{SURFACE PREPARATION TECHNIQUES}

There are numerous different surface preparation techniques that have been proposed and used in industry. Based on the underlying mechanism, three techniques have been identified: mechanical surface preparations, chemical surface preparations, and laser surface preparation.

\subsection{MECHANICAL SURFACE PREPARATIONS}

Mechanical surface preparations are generally for cleaning purposes. Physical contact with the surface is used to clean the prepared surfaces of grease, oil, dirt, rust, paint and other contaminants. The main techniques include wire brushing, sanding, and blasting. There are some standards for surface preparation before application of coatings using mechanical techniques - refer to the standards: SSCP-SP2, SSCPSP3, SSCP-SP11, SSCP-SP15 and ISO 8501[3]. 


\subsubsection{Wire brushing}

A wire brush tool consists of bristles most often made of steel wire. The steel used is generally a mediumto high-carbon variety and very hard and springy. Wire brushing can be a hand tool with a handle or can be formed into a wheel or some other tools to work as a machine.

\subsubsection{Sanding}

Sanding is usually used on non-porous surfaces to thoroughly abrade the surface. It can be done by hand or by power tools. For different applications, the sanding particle sizes and roughness can be different.

\subsubsection{Blasting}

Abrasive blasting is a more effective way to clean the surface with high-pressure sand, grit or liquids. The blasting can remove the solid surface dust but also soluble corrosion products. One example is vapor honing. Vapor honing is satisfactory when minimum reduction is desired in metal thickness. In this method, powdered abrasive material is propelled by high velocity water or steam against the surface.

\subsection{CHEMICAL SURFACE PREPARATIONS}

Chemical surface preparations are very widely used prior to adhesive bonding. The chemical preparations can not only clean the surface but also provides some desired functional surface conditions for the surfaces (such as to ensure wetting of the surface by the adhesive). Chemical surface preparations usually have more complicated processes compared to mechanical preparation and careful handling of the chemicals is required. The main techniques include plasma treatment and chemical etching.

\subsubsection{Plasma surface treatment}

The popular plasma treatment is air plasma, also known as Corona treatment. It is a surface modification technique that uses a low temperature corona discharge plasma to impart changes in the properties of a surface. Another more effective alternative way of plasma surface treatment is atmospheric pressure (air) plasma (APP). APP has a much greater plasma density and it is one of the most effective surface treatment process for cleaning, activating or coating Error! Reference source not found.. APP also improves low surface energy levels to as high as achieving complete wettability.

\subsubsection{Chemical Etching}

Etching is traditionally the process of using strong acid or mordant to cut into the unprotected parts of a metal surface. Etching as a surface treatment immerses a metal substrate in an aqueous acid solution. The purpose of etching is to clean the surface, especially the loose layer of oxide. The material, the type of oxide and adhesion needs to be carefully considered to choose the proper acid.

\subsection{SURFACE PREPARATION USING LASER}

Laser-based surface preparation uses an interference technique to texture the surfaces of Aluminum and Copper in a controlled and predetermined manner. This creates "rough" surfaces with pre-engineered series of ridges and valleys at the submicron scale before coating or adhesive bonding operations begin.

Two techniques, are illustrated in Figures 1 and 2: 


\subsubsection{Interference technique}

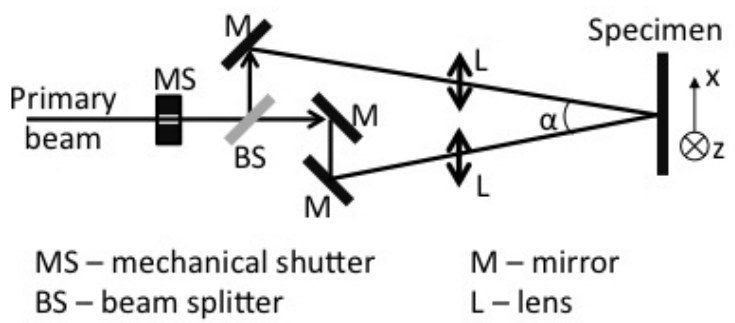

Figure. 1 Schematic setup of laser-interference system

\subsubsection{Traditional one-laser beam}

(a)(b) MS-mechanical shutter, M-mirror, L- lens

Figure. 2 Schematic of traditional one-laser beam system

For the one-beam setup, two mirrors will be used in order to minimize the setup time to/from the twobeam laser interference setup, the incidence angle with respect to the normal to the sample surface of $3^{\circ}$.

\section{SURFACE PREPARATION PROCESSES}

This project will focus on using adhesive bonding between aluminum and copper heat exchanger component to replace the traditional bonding methods. In this section, specific surface preparation processes for aluminum and copper are introduced that will be compared to the laser structuring approach.

\subsection{ALUMINUM AND ALUMINUM ALLOY SURFACE PREPARATION FOR ADHESIVE BONDING}

The standard industry practice of surface preparation for adhesive bonding used to be the Forest Products Laboratory etching, commonly referred to as FPL etch Error! Reference source not found.. However, this method uses chromates and dichromates that are no longer allowed in many countries Error!

Reference source not found.. There are many other methods modified from the FPL etch, such as the 
optimized FPL etch, the phosphoric acid anodizing (PAA) process, the P and P2 etchants, and the chromic acid anodize procedures Error! Reference source not found.Error! Reference source not found.Error! Reference source not found.. Different materials, chemicals and equipment are used by these methods, but the general processes and purposes are quite similar. A summary of the main steps of these methods is given below:

\subsubsection{Degreasing}

Remove any marks, oil, grease by wiping using safety solvent, vapor degreasing, emulsion cleaners, or alkaline degreaser.

\subsubsection{Alkaline cleaning}

Immerse the aluminum in the alkaline cleaning solution. Following the alkaline cleaning, a thorough water rinsing can be done if necessary. The process can be repeated if necessary. The detailed cleaning solution, temperature, and other conditions can be different based on the method.

\subsubsection{Etching (Deoxidation)}

Immerse the aluminum in the etch solution for certain amount of time and follow the etching with a thorough water rinsing. The total immersing time for the parts should be limited.

\subsubsection{Rinsing}

Rinse all the parts in water. The temperature and time of rinsing can be different per the specific method.

\subsubsection{Drying}

Air dry the aluminum if necessary.

As an example, the P2 etch (Sulfo-Ferric Etch) procedure Error! Reference source not found. is given below, considering its relative safety and ease:

1. Alkaline cleaning: Immerse the parts in alkaline cleaning solution for 5 mins and keep the temperature between 50 to $80^{\circ} \mathrm{C}$. Rinse in water after immersing. This process can be repeated. The non-etch alkaline solution should be prepared and used in accordance with the manufacturer's recommendations.

2. Etching: Immerse the part for $10-12$ mins at a temperature from 60 to $65^{\circ} \mathrm{C}$. Follow the etching by rinsing with room temperature water. This process can be redone no more than twice. The total immersion time should not exceed 34 mins. Etching solution: $\sim 27$ to $36 \%$ by weight of sulfuric acid ( 22 to $35 \mathrm{~g} / \mathrm{L}$ of ferric iron or 135 to $165 \mathrm{~g} / \mathrm{L}$ of ferric sulfate). Note: Only virgin ferric sulfate solution shall be used in this process. Impurities in reclaimed ferric sulfate will cause unwanted reactions when the aluminum is treated.

3. Final rinse: Rinse the parts for $1-2$ mins in water from room temperature to $50{ }^{\circ} \mathrm{C}$.

4. Air Dry: No more than 1 hour at temperature no more than $65^{\circ} \mathrm{C}$. 


\subsection{COPPER AND COPPER ALLOY SURFACE PREPARATION FOR ADHESIVE BONDING}

Copper, brass (alloy with zinc) and bronze (alloy with tin) are very common materials in heat exchangers and they can be used for high performance adhesive bonding. Copper has a tendency of forming brittle amine components with curing agents from some adhesive systems. The most common and successful surface treatment is black oxide, which is especially recommend when the adhesive is corrosive to copper. Note that this method is mainly for relatively pure copper alloys containing more than $95 \%$ copper Error! Reference source not found.. The procedure is given below:

1. Degrease.

2. Immerse in etching solution for a short time at room temperature. Solution: 30 parts of nitric acid (70\% technical) and 90 parts of water by volume.

3. Rinse the parts in running water and then immerse in copper stabilization bath for 2-3 mins. The stabilization components: sodium chlorite $31.6 \mathrm{~g} / \mathrm{L}$, trisodium phosphate $10.5 \mathrm{~g} / \mathrm{L}$, sodium hydroxide $5.3 \mathrm{~g} / \mathrm{L}$.

4. Rinse thoroughly in running water to reach a neutral result using $\mathrm{pH}$ indicator paper.

5. Air dry.

6. Bond as soon as possible.

Other methods for copper bonding including nitric acid etching, etc. Error! Reference source not found.. For brass, sandblasting or other mechanical means can be used; the flowing procedure is one example that combines both mechanical and chemical methods [1Error! Reference source not found.]; other methods are also available Error! Reference source not found.:

1. Mechanical blast. Particle size is not especially critical

2. Rinse with deionized water

3. Treat with a $5 \%$ solution of sodium dichromate in deionized water

4. Rinse in deionized water

5. Dry

The method given above for brass is also viable for bronze.

\subsection{LASER STRUCTURING}

The surfaces will be laser-structured in as-received condition, i.e., without any additional surface preparation steps. The laser-interference structuring will be conducted in two modes:

\subsubsection{Rastering mode}

The two-laser beams will be focused on the same area while the specimen will be continuously moved by two translation stages in the vertical and horizontal directions with given speeds.

\subsubsection{Spot-by-spot mode}

The two-laser beams will be held over each spot for a certain amount of time while the laser will fire a certain number of shots. After a spot would be processed, the specimen will be translated such that another area next to the previous spot will be laser processed.

The surface structuring using traditional one-laser beam system will be conducted using only rastering mode, in which the sample will be moved at constant speed while laser beam will be firing shots at 
constant frequency. The rastering will be preferred over spot-by-spot as this rastering technique is more productive than that spot-by-spot, i.e., the surfaces can be structured in a shorter amount of time.

\section{FUTURE WORK}

Surface preparation techniques specific to the adhesive bonding of Copper and Aluminum have been highlighted. The resultant surfaces will be characterized in terms of surface roughness and level of cleanliness. This information will act as a boundary condition for future finite element modeling of the joining geometries.

\section{REFERENCES}

[1] American Society for Testing and Materials (ASTM), D907, Standard definitions of terms relating to adhesives, Vol 15.06, Annual Book of ASTM Standards, 2008.

[2] R.F.Wegman, and D.W.Levi, Structural adhesive processing, Part B, Chapter 22, Section V Materials and Processes, Marcel Dekker Inc., New York, NY, 1177-1191, 1985.

[3] International Paint Ltd., Surface preparation: Metallic surfaces. http://www.internationalpc.com/information-centre/documents/surface-preparation.pdf

[4] T. Gilbertson, Enercon industries, atmospheric plasma. What is it? and What's it good for? ENEWS Surface Treating Technology, 2nd Quarter, 2001. [LẸ:

[5] H.W. Eickner, N.E. Schowalter, A study of methods for preparing clad 24 s-t3 aluminum alloy sheet surfaces for adhesive bonding, Forest products laboratory report No. 1813, 1950

[6] J.M. Chen, T.S. Sun, J.D. Venables, R. Hopping, Effect of fluorine contamination on the microstructure and bondability of aluminum surfaces, SAMPE NSS\&E 22, 25-46, 1977.

[7] American Society for Testing and Materials (ASTM), D2651-01, Standard recommended practice for preparation of metal surfaces for adhesive bonding. Vol 15.06. Annual Book of ASTM Standards, 2008.

[8] American Society for Testing and Materials (ASTM), D3933, Standard practice for preparation of aluminum surfaces for structural bonding, Annual Book of ASTM Standards

[9] R. F. Wegman and J. V. Twisk, Aluminum and Aluminum Alloys in Surface preparation techniques for adhesive bonding (Second Edition), William Andrew Publishing, 2013.

[10] W.J. Russell, E.A. Garnis, A chromate-free low toxicity method of preparing aluminum surfaces for adhesive bonding, SAMPE J 17 (3) 19-23, 1981.

[11] S. Ebnesajjad, 6 - Surface Preparation of Metals, In Handbook of Adhesives and Surface Preparation, Plastics Design Library, William Andrew Publishing, Oxford, 83-106, 2011. Rogers NL. Surface preparation of metals for adhesive bonding. In: Bodnar MJ, ed. Applied Polymer Symposia No. 3, Structural Adhesives Bonding. New York, NY: Interscience Publishers, 327-340, 1966. 
